\title{
Outdoor Play Experiences for Young First Nation Children in Nova Scotia: Examining the Barriers and Considering Some Solutions
}

\author{
Elizabeth Munroe and Alanna MacLellan-Mansell
}

Elizabeth Munroe is an assistant professor at St. Francis Xavier University in Antigonish, Nova Scotia. She holds a PhD in early childhood education from the University of Calgary. Elizabeth's research interests revolve around teacher learning as it relates to school improvement. This article derives from a research grant with the First Nations Student Success Program, in conjunction with Mi'kmaw Kina'matnewey in Nova Scotia. Email: emunroe@stfx.ca

Alanna MacLellan-Mansell is a student in the bachelor of education program at St. Francis Xavier University in Antigonish, Nova Scotia. She holds an MA in sociology from the University of Victoria in British Columbia.

Despite the many known benefits of outdoor play, early childhood educators are often reluctant to take children outdoors. We have been examining this issue as part of collaborative school improvement work with early childhood educators in First Nation communities in Nova Scotia. In this article, we first present a review of related literature and then share information gathered from educators related to the barriers to taking children outdoors. Finally, we propose four processes that encourage and support educators as they reconsider the challenges and reexamine the potential of this crucial area of experience for young children.

\section{Acknowledgments}

Thank you to Kyle Denny, FNSSP school improvement coordinator, Rena Falls, director of the Acadia First Nations Child Care Centre, and Mindy Gallant-Zwicker, director of the Three Wishes Annapolis First Nations Child Care Centre for suggestions and comments on this article.

Outdoor play is beneficial for young children (Louv, 2005) and young children usually enjoy opportunities to spend time outdoors. Furthermore, most early childhood programs operate under policies and standards of practice that regulate the time children spend outdoors. However, despite these strong reasons to include outdoor play in their programs, early childhood educators are often reluctant to take children outdoors (Davis, Greenfield, Harris, Starbuck, \& White, 2011). In our work with early childhood educators in First Nation communities in Nova Scotia, we heard widespread agreement about the importance of outdoor play experiences and recognition of cultural connections to the land, but participants often mentioned barriers to providing enriching outdoor play experiences.

In this paper, we review the benefits of outdoor play in terms of enhancing the multilayered development of individual children and in relation to deeply held Aboriginal cultural relationships with the land. We review challenges to taking children outdoors, as discussed in the published literature, and we relate these to our conversations with early childhood educators in 11 First Nation communities in Nova Scotia. In particular, we examine the data gathered during one workshop regarding educators' perceptions of barriers to taking children outdoors. Finally, we propose four processes that encourage and support educators as they reconsider the challenges and reexamine the potential of this crucial area of experience for young children.

Of the 70 educators with whom we collaborate, 96 percent are First Nation, and all of the parents and children they work with are First Nation. However, we believe the issues explored in this paper are not particular to First Nation contexts. As the literature demonstrates, barriers to taking young children outside exist in many communities in the world, so we suggest that the processes to encourage and support change in this area of practice would be appropriate and helpful for many directors and educators in a wide variety of settings.

\section{Children Spending Time Outdoors- What Do Others Say About the Benefits?}

The early childhood education literature is replete with articles extolling the benefits of being outside. One area of focus is the skills, attitudes, and knowledge individual children gain through experience outdoors. For instance, outdoor spaces that provide a variety of play options, such as imaginative/dramatic play, building, digging, running, jumping, swinging, and climbing, offer children the opportunity to develop both physically and socially and to enhance their reasoning and observation skills (Clements, 2004; Handler \& Epstein, 2010; Nature Action Collaborative for Children, n.d.; Stephenson, 2003). Outdoor play also develops children's independence by giving them the freedom to explore without the interference of adults (Handler \& Epstein, 2010; Kernan, 2010; Little \& Eager, 2010). For children with symptoms 
of attention deficit hyperactivity disorder, frequent outdoor play - especially in green spaces - provides crucial sensory input that enables the children to maintain focus (Handler \& Epstein, 2010; Nature Action Collaborative for Children, n.d.). Outdoor play also reduces aggressive behaviour and bullying, as long as the space is of an adequate size (Handler \& Epstein, 2010; Lambert, 1999).

Much of the literature we reviewed reveals the developmental advantages of childhood exposure to the challenges posed by the outdoors, particularly in the natural environment (Dowling, 2010; Fjørtoft, 2001; Handler \& Epstein, 2010; Miller, 2007; Moore, 1997; Rivkin, 1997; White, 2004). Play in nature offers varying degrees of risk or challenge, thereby giving children the opportunity to determine their physical or social limits and to choose whether to challenge themselves further (Almon, 2009; Copeland, Sherman, Kendeigh, Kalkwarf, \& Saelens, 2012; Handler \& Epstein, 2010; Miller, 2007; Nature Action Collaborative for Children, n.d.). For Little and Eager (2010), this opportunity was crucial because willingness to take a risk is "fundamental to human learning as we endeavor to develop new skills, try new behaviors, develop new technology, and abandon the familiar to explore what we know less well" (p. 499). In the absence of natural settings, some authors argue that play areas and structures can be designed and built to incorporate nature and provide opportunities for challenge, if they are created with the management of risk in mind rather than its elimination altogether (Little \& Eager, 2010; Sandseter, 2009).

In addition to benefiting children's physical and social development, active outdoor play has been found to promote health in ways that popular indoor screenbased activities cannot. During the crucial period of greatest physical growth between the ages of 3 and 12, children's muscles, heart, lungs, brains, and other organs are strengthened greatly through energetic activities associated with outdoor play (Clements, 2004). Vigorous play has also been linked to stimulation of the digestive system, improved appetite, and the bodily strength and growth that results (Clements, 2004). Physical activity reduces childhood overweight and obesity, which has lasting benefits for cardiovascular and muscular health and endurance, as well as decreasing depression and anxiety (Tucker, 2008). Perhaps most importantly, active play in these early years has been linked to the formation of positive associations with physical activity and children's continued engagement in active and healthy lifestyles into adulthood (Clements, 2004; Handler \& Epstein, 2010; Tucker, 2008).

Spending time outdoors has implications beyond benefits to individual children. Louv (2005) claims that "the health of the earth is at stake.... How the young respond to nature, and how they raise their own children, will shape the configurations and conditions of our cities, homes - our daily lives" (p. 3). When children spend time outdoors, they are more likely to develop an environmental ethic or a sense of stewardship for the earth (White, 2004), which contributes to ecoliteracy, one of the literacies thought to be essential for the 21 st century (21st Century Schools, 2010, para. 3).

Much of the foregoing literature is derived from mainstream research on individual child development. These writings are pertinent to early childhood educators and families in First Nation communities as they strive to enhance each child's intellectual, social, and physical health, but they overlook the cultural significance of the outdoors and the land to Aboriginal people. The Assembly of First Nations (n.d.) describes the special relationship Aboriginal people have with the earth and all living things in it as a "profound spiritual connection to Mother Earth" (para. 2). Greenwood and Shawana (2003) insist that traditional values and beliefs should be the "fundamental building blocks" of programs for young children (p. 60). They quote one of their study participants who emphasized that including the natural environment in child care settings would promote holistic learning, "a reflection of who we are" (p. 58). Certainly, several parts of the Nova Scotia Mi'kmaq Child Care Facility Guidelines (Nova Scotia Child Care Initiative Program Technical Group, 1998) reflect the cultural value placed on the land and nature. For example, the guidelines state:

- Mi'kmaq language and culture can be reinforced through activities related to the environment: taking special field trips; picking berries; setting up a small teepee, etc.

- Outside play is encouraged as children need a minimum of one (1) hour a day for physical well-being. Mi'kmaq philosophy in regards to child development puts an emphasis on connecting to nature. Fresh air and sunshine are necessary elements for social, spiritual, physical, and emotional development. (p. 9)

\section{What Discourages Educators from Taking Children Outdoors?}

Despite the many known benefits of outdoor play, many children do not spend as much time playing outdoors when compared with previous generations (Handler \& Epstein, 2010; Kernan, 2010; Rivkin, 1997; Tucker, 2008; White, 2004). Inadequate or impoverished outdoor play spaces attached to child care centres can be one kind of barrier (Staempfli, 2009). When the square footage of play space is less than the recommended guideline, or when the space has few provocations for interaction - either with fixed or moveable structures and props - children may not find it positive to be outside.

Other barriers to outdoor play relate more to educators' attitudes and fears. Beliefs about weather are often a barrier to outdoor play (Copeland et al., 2012; Cuencas, 2011; Kernan, 2010). In much of North America, rain, snow, or cold can be perceived as reasons to stay indoors, thereby limiting children's outdoor play opportunities. In some locations, such as Iqaluit, Nunavut, the daily use of outdoor 
environments is central to the operations of daycares, demonstrating that some communities experiencing difficult weather continue to make outdoor play a priority (McNaughton, 1995). Elsewhere, in countries such as Sweden and Norway where outdoor kindergartens are increasingly popular, weather is not seen as an impediment (Fjørtoft, 2001; New, Mardell, \& Robinson, 2005; Litmus Films, 2008). There, children and adults dress for the weather and continue to play and learn outside in all weather conditions.

Perhaps the most pervasive barrier is concern for children's safety. Fears of accidents and falls, kidnapping, sun exposure, air pollution, insect bites, contact with garbage, and a plethora of other safety concerns have prevented adults from encouraging children to play outside (Clements, 2004; Copeland et al., 2012; Dwyer, Higgs, Hardy, \& Baur, 2008; Handler \& Epstein, 2010; Kernan, 2010; Moore, 1997; Stephenson, 2003; White, 2004). Despite the acknowledgement of the benefits of providing challenges for young children, as discussed above, play spaces or equipment often offer little to no risk because of more stringent safety regulations for outdoor play areas. Such low-risk environments can lead children to play in dangerous ways as they seek appropriate challenge (Almon, 2009; Copeland et al., 2012; Dwyer, Higgs, Hardy, \& Baur, 2008; Kernan, 2010; Stephenson, 2003). Adults' worries about injury during outdoor play can lead to restrictions on the amount of children's free mobility, since injury prevention has come to overshadow injury management (Kernan, 2010; Sandseter, 2009). Some suggest that this situation stems from fears of litigation, so prevalent in North American society; these fears, in turn, pressure educators to dissuade children from taking beneficial and developmentally appropriate risks (Almon, 2009; Little \& Eager, 2010; New et al., 2005). In countries such as Italy, where litigation resulting from injury is rare, children have been more likely to have opportunities to challenge themselves (New et al., 2005). Conversations with early childhood educators and directors in Norway also made it evident that litigation related to outdoor play is rarely an issue in Norway (personal communications, March, 2012). ${ }^{1}$ Safety concerns can be exacerbated by the lack of adequate outdoor space offered by many child care facilities. A lack of space can result in a dearth of private spaces to hide alone or with friends, increased stress and aggression among children, and potentially injurious collisions (Lambert, 1999; Mauffette, 1998). As a consequence, adults may come to see the outdoor space as an area of stress and choose to remain indoors instead, where safety can be more comfortably monitored (Kernan, 2010; Lambert, 1999; Mauffette, 1998).

In addition to safety concerns, educators, parents, and community adults may lack conviction that learning and development occur through outdoor play (Dwyer et al., 2008; Lambert, 1999; Mauffette, 1998). This notion has its roots in Spencer's 19th-century surplus energy theory, which considered children's outdoor play simply as a means to work off excess energy (White, 2004). As a result of Spencer's theory, White (2004) explains, "playgrounds are seen as areas for physical play during recess, where children 'burn off steam,' and not for the other domains of development or for learning" (p. 1). In reality, outdoor play provides authentic and rich learning experiences not replicated indoors (Dowling, 2010; Miller, 2007), and children who spend time in welldesigned, nature-filled outdoor spaces with nurturing adults develop valuable skills across all learning domains (Miller, 2007). Belief in the value of outdoor play for providing learning opportunities is perhaps best evidenced through Norway's nature kindergartens, where children spend much, if not all, of their time learning outdoors (Aasen, Grindheim,
\& Waters, 2009; Fjørtoft, 2001; Litmus Films, 2008; Sandseter, 2009).

Educators' attitudes about being outside can be a significant predictor of children's experiences and attitudes about learning outside (Stephenson, 2003). Educators' concerns about weather or safety affect children's views of outdoor play by suggesting when it is appropriate to go outside or what it is appropriate to do there (Cuencas, 2011). Research indicates that pressure from parents to keep children completely injury free and to focus on academic skills creates the impression among some educators that outdoor play has little place in their program (Copeland et al., 2012). This mindset affects children's outdoor experiences by situating educators as mere supervisors rather than as learning facilitators and by placing limits on the allotment of time for outdoor activities (Lambert 1999; Moore, 1997). Conversely, educators with positive attitudes about the learning that can occur outdoors have a tendency to overcome barriers and to build time outdoors into the day (Aasen et al., 2009; Davis et al., 2011; Litmus Films, 2008; Fjørtoft, 2001; McNaughton, 1995; Sandseter, 2009).

In communities where the educators, children, and families are First Nation, it might be assumed there would be fewer barriers to children spending time outdoors, and that it would be a high priority because of strong cultural connections to the land. However, as Stairs and Bernhard (2002) explained, there is considerable complexity inherent in education for Aboriginal children because of the need to intertwine the goals of mainstream academic success with "the essential establishment of children's identity valuing and giving expression to Aboriginal cultures" (p. 309). Comments made by Elders when child care centres and Aboriginal Head Start programs were created on reserves in the late 1990s illustrate this complexity (Greenwood \&

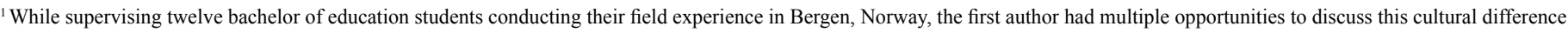
regarding children's safety and responsibility when outdoors. 
Shawana, 2003). Some Elders expressed concern that these programs would be a sort of residential-school experience for the youngest members of their communities. Rowan (2011) agrees that a community's adherence to mainstream regulations may colonize the programming for young children in Aboriginal communities. Greenwood and Shawana's work sought to define quality child care for First Nation children in terms of the communities' priorities. However, Greenwood (2009) notes that "one of the greatest challenges facing early childhood caregivers is to take principles of Indigenous knowledge and actualize them in current practice" (p. 75).

This review of the literature provides strong evidence of the benefits and importance of outdoor play for all children, but it has also revealed educators' hesitation and the complexities in taking the children outdoors (Almon, 2009; Handler \& Epstein, 2010). Considering the strong traditional Aboriginal identification with nature and the land, it might be assumed that the First Nation early childhood educators with whom we have collaborated would readily embrace taking the children outdoors. In reality, these women experienced similar barriers to those described in the mainstream literature, as will be discussed below.

\section{Two Professional Learning Workshops}

As part of an ongoing research study in partnership with the Mi'kmaw Kina'matnewey (MK) First Nation Student Success Program (FNSSP) in Nova Scotia, professional learning opportunities have been offered for early childhood educators, with a specific emphasis on programming for children in the year before they enter formal schooling. In addition to visits to the communities and initial collaborative work with specific individuals, two full-day workshops, one year apart, have been held. The primary purpose of these workshops has been to facilitate collaboration and networking among the educators on the topics of language and cultural enrichment. As part of the emphasis on increasing programs' cultural relevance, the workshops included discussions about the benefits of and barriers to providing enriching outdoor play experiences for the children. Prior to the first workshop, the researchers and the FNSSP coordinator had visited many of the communities. When asked in what area they felt improvement was needed, some of the educators had expressed frustration with their outdoor play spaces, and they had asked questions about designing new outdoor areas. Although none of the educators or directors specifically linked their interest in improving outdoor play with the Aboriginal context in which they worked, the FNSSP coordinator affirmed that, in his view as a First Nation person, children's connection to nature was very important. A focus on taking children outdoors was seen as an extension of the focus on the programs' cultural enrichment.

Thirty early childhood educators and directors from eight First Nation communities in Nova Scotia attended the first all-day workshop organized under the auspices of the partnership. As part of the workshop, the first author shared photos and information from a recent trip to Sweden, where she had visited child care centres with extensive and interesting outdoor spaces. As well, participants viewed the video, Leave No Child Inside (Harvest Resources, 2006), which included inspiring photos of naturalistic outdoor play spaces for young children as well as research-based information on the benefits of outdoor play.

During the year after the first workshop, the researchers and the FNSSP coordinator continued to visit communities and collaborate with the early childhood educators. It became obvious that while directors and educators were enthusiastic about increasing the time children spent outdoors and were interested in alternative play spaces, they were meeting considerable barriers to achieving that goal. At some meetings, the topic of "catalogue" style versus natural play spaces arose, and at other meetings, some educators described some tension with regard to increasing outdoor play time. With candour, they admitted to their personal dislike of taking children outdoors and their belief that outdoor experiences were not as crucial as the indoor learning time. These discussions influenced the decision to continue a focus on outdoor play in the second annual workshop.

Seventy-five educators from all 11 First Nation communities associated with MK attended the second full-day workshop. Most early childhood programs closed for the day, and almost all the educators working in First Nation communities received approval to attend the event. Interactive experiences were offered to reach the participants on an emotional as well as an intellectual level (Keeler, 2004). We showed a segment entitled "Exploring the Natural World" from the DVD Our Children, Our Ways: Early Childhood Education in First Nations and Inuit Communities (Red River College, n.d.), which was very well received by the group. The images and the encouraging narrative underscored the role of early childhood educators in assisting Aboriginal children to learn about their cultural connections to nature and to the land.

At another point in the workshop, everyone selected a smooth beach stone to hold while listening to and viewing the illustrations from If You Find a Rock by Christian and Lember (2000). Then, the educators reflected on and discussed their own memories of playing outdoors. The room filled with conversation as the participants reminisced about their positive outdoor play experiences and commented with regret and concern on the few hours children spend outside nowadays. The participants watched a slide presentation that reviewed information about the benefits of children spending time outdoors and examined some of the possible reasons that children are not playing outdoors as much now as in the past (Nature Action Collaborative for Children, n.d.). There was widespread agreement among the educators that 
children should be spending more time outdoors, for individual and cultural reasons.

\section{Examining Barriers and Proposing Solutions}

At this point in the second workshop, the participants were randomly assigned to small groups and asked to record on poster paper all the barriers that they believed prevented or limited their taking young children outside in their centres. The barriers listed by the 12 groups are represented in Figure 1. This graph shows the frequency of the responses and offers examples of the participants' specific concerns in each category. All of the barriers identified by the early childhood educators in these First Nation communities were similarly identified in the literature reviewed above. The workshop participants clearly recognized the problems associated with weather, educators' and parents' attitudes and fears, and inadequate or dangerous outdoor play spaces. Interestingly, no group identified children not wanting to go outdoors as a barrier!
Subsequent to identifying barriers to taking children outdoors, each group was asked to look at another group's list and propose solutions to those listed barriers. In only a couple of minutes, many practical solutions came forth, ranging from personal actions to community initiatives. For example, with regard to the barrier of children who run away, there were suggestions to improve supervision, use a harness, give the children special jobs, employ a special assistant, or install a fence. Considering the ease with which participants offered solutions, one might assume that all the barriers to taking the children outdoors would be removed once the participants returned to their communities. However, such an assumption overlooks several layers of complexity.

Figure 1. Barriers to outdoor play, as described by early childhood educators taking part in a workshop in Nova Scotia, Canada. Numbers in the chart indicate how many of the 12 groups listed this circumstance as a barrier.

\section{Barriers to Outdoor Play}

OTHER: no time, lure of computer games

ALLERGIES: sun, flies, bees

PEOPLE: children run away, short staffed, adults fears for safety

PROPER CLOTHING: no warm/dry clothes

ANIMALS: roaming animals, insects

WEATHER: rain, cold, hot, UV rays

OUTDOOR ENVIRONMENT: broken/lack of equipment, garbage, vandalism

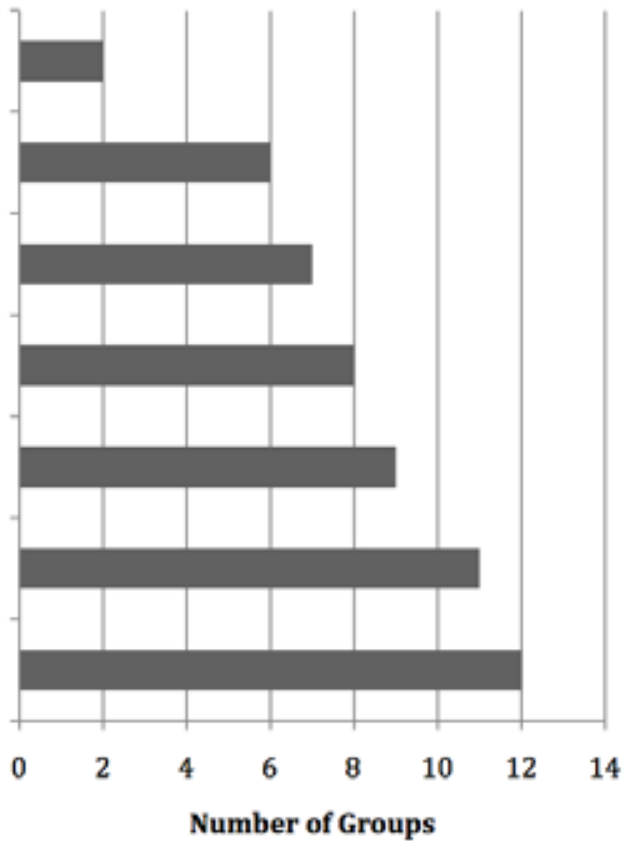

In some instances, when one group examined the barriers listed by another group, people maintained that some items on the list were not barriers at all. For example, one group had listed puddles on the playground as a barrier to taking the children outdoors. The next group disagreed and suggested that puddles offer an interesting play opportunity. Others commented that the lack of appropriate clothing for the children was not a barrier; their centre had a supply of outdoor clothing to lend so that children were not prevented from going outdoors.

The educators who perceived certain constraints as barriers were not simply conjuring up excuses. As Bernhardt (2004) writes, "All of us have perceptions of the way the world operates. We act upon those perceptions everyday as if they are reality" (p. 54). Therefore, the views of those educators who saw these issues as real barriers merit respect. As well, ignorance concerning the extent of some barriers, such as puddles on specific playgrounds, must be acknowledged. Perhaps the puddles were deep, extensive, and filled with mud, and as such offered a particular challenge to the educators taking the young children to the space. Perhaps the educators were following the suggestions in the First Nations Head Start Standards Guide regarding eliminating water in the outdoor play space (Health Canada, 2001). Finally, in the case of the educators who had a ready supply of children's outdoor clothes, the fact that that they had already faced a barrier and found a solution should be celebrated.

\section{Considering Next Steps}

The workshop participants completed a detailed feedback form at the end of the second workshop. They were asked to comment on the ideas discussed in the workshop and to explain whether or not they hoped to make any changes in their work regarding outside play space and/or taking children outdoors. The majority of participants stated that they had found the conversations and resources to be useful, informative, and inspiring. Some added 
that they had not previously thought about the possibilities for learning through outdoor play and that the workshop had opened the door to new practices. Participants acknowledged that outdoor play could incorporate Mi'kmaw culture and suggested that Elders could visit to discuss the importance of nature.

The notion of natural play spaces, as highlighted in some of the resources, captivated many participants' interest, with some highlighting the welcoming appearance and simplicity of playthings such as tires, wood, or dirt. Participants noted the current lack of comfort outdoors and expressed the desire to create spaces with shade, such as gazebos or outdoor tables, where children and adults alike could relax and chat. Of those who expressed these interests, only a few believed that space and resource concerns would inhibit them from moving forward with new initiatives.

Many participants indicated that they could see themselves making an initial change in their practice by "bringing the outdoors indoors." They noted that children love going for walks and so it would not be difficult to spend more time picking up items in nature, discussing them, and bringing them back into the classroom. One educator remarked, "I am going to make a science centre with outdoor things - branches, rocks, moss, etc." Others resolved to have more plants and perhaps a fish tank inside their centre.

A small number of participants indicated that they would not change their practices. Some reported that they felt a lack of agency at their workplace because they were not able to make decisions. However, these individuals also indicated that they intended to make suggestions to their directors or other supervisors in the hopes of effecting change.

Six months later, the authors sent a followup email to participants asking if they had thought more about the information and experiences shared during the second workshop and requesting an update with regard to taking the young children outdoors. Although the response rate was low, one message was particularly exciting. The centre director wrote:

We are in the phase of getting more added to our playground.... We have looked at the books and found great ideas as to what we'd like to implement in terms of play outdoors. We're waiting on funding for [a] new swing set. Ideally, we'd like a bike trail, little hill for sledding, and a tunnel. We do have an area set out for a medicine/ flower garden. We're excited for our new additions.

\section{Possible Processes to Encourage and Support Change}

The comments on the feedback forms from the second workshop illustrated a very encouraging positive response to the information about outdoor play shared throughout the day together. However, a workshop's success is found, not in the feedback forms, but rather in actual changes in practice (Guskey, 2000). We know we cannot ignore the long lists of barriers the educators created and we cannot assume that all the tensions regarding taking children outdoors were erased through the workshop experience. For educators to reflect on and perhaps change their practices, ongoing information, encouragement, and support are needed (Fullan, 2007).

We suggest four processes as next steps to encourage and support change in young children's outdoor play time. It is important to note that these processes rarely depend on external experts. The first suggestion, offering professional learning opportunities, may rely on external resources to some extent, but overall, the discussions and experiences that occur should be primarily an opportunity for educators to network, collaborate, reflect, and make plans for next steps in their communities.

\section{- Offer professional learning opportunities to build awareness}

A single professional learning event such as a workshop may not change practice (Joyce \& Calhoun, 2010), but a single event does hold the potential for building awareness. Through our two annual workshops described above, we observed that a cycle was started, with awareness leading to action, which led in turn to more widespread awareness and, ultimately, to more action.

During our first workshop, participants viewed slides of innovative natural play spaces. One child care director exclaimed with regret that she had just purchased a play set from a glossy catalogue; she had not known about nature-based materials and equipment for outdoor play spaces. Perhaps White (2004) was thinking about people like this director as he observed that "when most adults were children, playgrounds were asphalt areas with manufactured, fixed playground equipment such as swings, jungle gyms and slides, where they went for recess. Therefore, most adults see this as the appropriate model for a playground" ( $p$. $1)$.

Inspired by the photos shared during the first workshop, this director applied for and received a grant for a new natural play space at her centre. At our second workshop, we showed photos of that new play space and the educators from that location participated in an interactive conversation about their experience in changing their outdoor play area. All the people in the room seemed to be inspired by the way that the dream for change had become a reality for one of their sister communities; the possibility for change in their own communities seemed more possible. As we found out through our email correspondence six months later, another community was in the midst of changing their outdoor space to include more natural elements. This series of events illustrates the awareness-actionawareness-action cycle that we hoped for.

- Acknowledge and examine the past and current experiences of adults 
The second process we suggest to support and encourage change in children's outdoor play experiences is that directors and educators examine their past and current experiences with outdoor play. One barrier listed during our workshop activity was that "ECEs [early childhood educators] refuse to go outside." During another conversation, one First Nation educator commented frankly that she did not like going outside and wished she did not have to take the children out. In early childhood settings, the adults make the decisions whether or for how long the children spend time outdoors, despite regulatory policies. Why might an educator decide against going outdoors? What are the past and current experiences of the adults regarding outdoor play? The answers to these questions are pivotal to the decisions the adults make on a daily basis.

Many educators are part of a generation that has not spent hours playing freely outside and that has little nostalgia for being outside. Almon (2009) suggests:

It's time to move forward.... There are several good ways for adults to get started on this. One is to share play memories from one's own childhood. We remind ourselves that we are players at heart, and young teachers who may not have played learn from the older ones. When teachers share play memories with each other and with parents they help create a strong play culture in their school or child care center. (p. 44)

In collaborating with Aboriginal early childhood educators in Alaska, Hughes (2007) invited them to paint a representation of their childhood. Their representations led to an examination of core beliefs and values, one of which was a desire to have children spend a lot of time outdoors experiencing nature.

Attention to the adults' current experience while outside with the children is paramount in supporting outdoor play. Some of the educators we collaborated with mentioned broken benches and no shade as deterrents to their enjoyment of being outdoors with the children. We suggest centre directors and staff could examine outdoor space in terms of how it meets the adults' needs. Is there a place for adults to sit down, for example? Mauffette (1998) observes that "if the outside space is cramped, uncomfortable or stressful, adults will avoid it and spend minimal time outside.... Making the outdoors more enjoyable for everyone is of utmost importance" (p. 21).

\section{- Explore and share the adults'values, beliefs, and goals}

In discussions during community visits and the two workshops, we learned that educators placed considerable emphasis on the learning that should occur when children are attending organized early childhood programs. Educators commented that they felt the need to spend the time "teaching" the children in order to prepare them for school and they did not want to interrupt this teaching by taking the children outdoors. Such comments were especially common among those who worked in half-day programs. Educators from a wide variety of programs also believed that this was the expectation of parents and other adults in the community. However, during meetings held with parents and others in two communities, we heard strong agreement about the value of children spending time outdoors, learning some of the traditional ways of the (typically rural) communities. The adults of the community seemed to value outdoor play as well as school readiness experiences. Stairs and Bernhard (2002) emphasize the complexity inherent in Aboriginal education, as the students "must be competent in the skills and knowledge that will allow them to be successful in both the community of their birth and broader Canadian society" (p. 8). Early childhood educators have often received their certification through coursework that reflects a mainstream lens (the case until recently with most of the First Nation educators with whom we collaborate), and this state of affairs has introduced additional complexity. The resultant programming may be more "submersion education" (Bear Nicholas, 2011, p. 1) than culturally relevant education.

It might be assumed that children will spend some time outdoors once they are at home, but statistics indicate that this is not always the case (Copeland et al., 2012). If communities examine the extent of their children's outdoor play opportunities beyond experiences in organized programs, they may acknowledge the need to increase the time spent outdoors while children are in child care, Aboriginal Head Start, or kindergarten. As Gruenewald (2008) explains, "to develop an intense consciousness of places that can lead to ecological understanding ... children must regularly spend time out-of-doors building long-term relationships with familiar, everyday places" (p. 316).

Community collaboration and consultation is strongly encouraged in The First Nations Head Start Standards Guide (Health Canada, 2001), and is a central tenet of Aboriginal early childhood policy (Greenwood, 2006). Perhaps increased and targeted communication among all the adults (parents and educators) about time spent outdoors would lead to clarification of the goals of the various early childhood programs and discussion of the ways in which those goals might be achieved. Children may not learn the letters of the alphabet while they are outside, but they do develop social and physical skills, as well as vocabulary and language skills, that are important for school success. They may also develop a deeper understanding of their culture, which is "vital for educational success amongst Aboriginal youth" (Nguyen, 2011, p. 239). Through these community discussions, strong cultural values may become evident and changes to the experiences of the young children in organized programs may result. 


\section{- Reframe barriers in terms of problems and conditions}

Early childhood education centre directors and educators are constantly bumping up against the barriers to taking children outdoors that are particular to their location and then considering possible solutions. Sometimes this becomes a reactive process. To move into a more proactive approach, we suggest that child care centre staffs work with a model that incorporates Bernhardt's (2004) notions of ideal state, driving forces, restraining forces, problems, and conditions.

To begin, the staff would have to agree that the goal, or ideal state, is taking children outdoors for longer periods of time in enriched or natural play spaces. Staff members then would consider what forces are driving and restraining progress toward the ideal state. The main driving force toward this ideal state would be the strong belief in the value of children playing outdoors, while the restraining forces would be the various barriers experienced by staff members. To effect change in behaviour, Bernhardt (2004) proposes "gnawing away at the restraining forces, while strengthening the driving forces" (p. 176).

One way to gnaw away at the restraining forces, or barriers, is to think about whether they are problems or conditions. Bernhardt explains: "A problem is something we can do something about ... a condition is something that we cannot do anything about-we acknowledge it and go around it, but we do not waste time trying to change it" (p. 177). For example, the weather is a condition; the lack of proper clothing to go outdoors in that weather is a problem. After agreeing which of the barriers are conditions and which ones might be reframed as problems, stakeholders could develop an action plan that would facilitate progress toward the ideal state.

\section{Clarifying the Priorities}

Our review of the literature provided substantial confirmation of the benefits children reap from spending time outdoors. Emotional, social, fine and gross motor, creative, and intellectual development may be enhanced through exploration and play in outdoor settings. Mental and physical health benefits are also evident. Beyond benefits to individuals, some suggest that the ongoing health of our planet depends on children developing ecoliteracy. In the case of First Nation children, spending time outdoors and learning about and honouring their connectedness to and responsibility for the land reflects their communities' traditional beliefs and values.

Even though there is widespread agreement that children should spend significant periods of time outdoors, the literature and our research data suggest that many barriers prevent the realization of this ideal state. Questionable safety for the children, unpleasant experiences for the adults, and unclear goals for the programs may prevent or shorten the time that educators take the children outside, despite policies or regulations being in place and despite cultural values. In this article we have suggested four strategies or processes that may assist early childhood educators to overcome the barriers. These processes describe potential next steps in our collaborative work with the First Nation communities in Nova Scotia. The first three of these strategies are (1) increasing educators' awareness of the importance of outdoor play and the possibilities for outdoor play spaces through professional learning opportunities; (2) facilitating discussions wherein the adults' past and current experiences with the outdoors are examined; and (3) exploring staff members', parents' and communities' values, beliefs, and goals with regard to the educative experiences of their young children. Through these processes, we believe staff and community members will clarify where their priorities lie with regard to outdoor play experiences for their young children. Once the priorities are established, we recommend a fourth step whereby educators work through Bernhardt's (2004) process of reframing barriers in terms of problems and conditions to create an action plan to facilitate children playing outdoors in enriched play spaces.

\section{References}

21st Century Schools. (2010). Multiple literacies for the 21 st century. Retrieved from: http:// www.21stcenturyschools.com/What_is_21st_Century_ Education.htm

Aasen, W., Grindheim, L. T., \& Waters, J. (2009). The outdoor environment as a site for children's participation, meaning-making and democratic learning: Examples from Norwegian kindergartens. Education 3-13: International Journal of Primary, Elementary, and Early Years Education, 37(1), 5-13. doi:10.1080/03004270802291749

Almon, J. (2009). The fear of play. Exchange, 186, 42-44.

Assembly of First Nations. (n.d.). Honouring earth. Retrieved from: http://www.afn.ca/index.php/en/ honoring-earth

Bear Nicholas, A. (2011). Linguicide: Submersion education and the killing of languages in Canada. Retrieved from: http://briarpatchmagazine.com/ articles/view/linguicide

Bernhardt, V. (2004). Data analysis for continuous school improvement (2nd ed.). Larchmont, NY: Eye on Education.

Christian, P., \& Lember, B. (2000). If you find a rock. New York, NY: Harcourt.

Clements, R. (2004). An investigation of the status of outdoor play. Contemporary Issues in Early Childhood, 5(1), 68-80.

Copeland, K. A., Sherman, S. N., Kendeigh, C. A., Kalkwarf, H. J., \& Saelens, B. E. (2012). Societal values and policies may curtail preschool children's physical activity in child care centers. Pediatrics, 129(2). doi:10.1542/peds.2011-2102

Cuencas, J. (2011). Another day without play: A qualitative study exploring perceptions of outdoor play. Unpublished master's thesis, Florida State University. Retrieved from: http://etd.lib.fsu.edu/theses/available/ etd-04042011-234345/unrestricted/Cuencas_J_ Thesis 2011.pdf

Davis, T., Greenfield, C., Harris, L., Starbuck, S., \& White, T. (2011, May). Teaching with nature: Helping educators experience the joys of connecting children with nature. Paper presented at the World Forum on Early Care and Education 2011, Honolulu, HI

Dowling, J. (2010). Preschoolers and nature: Snug as a bug in a rug. Highscope Extensions, 25(2), 12-13. Retrieved from: http://membership.highscope.org/app/ issues/144.pdf

Dwyer, G. M., Higgs, J., Hardy, L. L., \& Baur, L. A. (2008). What do parents and preschool staff tell us about young children's physical activity: A qualitative study. International Journal of Behavioral Nutrition and Physical Activity, 5(66). doi:10.1186/1479-58685-66

Fjørtoft, I. (2001). The natural environment as a playground for children: The impact of outdoor play activities in pre-primary school children. Early Childhood Education Journal, 29(2), 111-117.

Fullan, M. (2007). The new meaning of educational change (4th ed.). New York, NY: Teachers College Press. 
Greenwood, M. (2006). Children are a gift to us: Aboriginal-specific early childhood programs and services in Canada. Canadian Journal of Native Education, 29(1), 12-28, 146

Greenwood, M. (2009). Places for the good care of children: A discussion of Indigenous cultural considerations and early childhood in Canada and New Zealand. Unpublished doctoral dissertation, University of British Columbia, Vancouver. Retrieved from: http://www.collectionscanada.gc.ca/obj/ thesescanada/vol2/BVAU/TC-BVAU-14838.pdf

Greenwood, M., \& Shawana, P. (2003). Whispered gently through time: First Nations quality child care. Native Social Work Journal, 4(1), 51-83.

Gruenewald, D. (2008). The best of both worlds: A critical pedagogy of place. Environmental Education Research, 14(3), 308-324.

Guskey, T. (2000). Evaluating professional development. Thousand Oaks, CA: Corwin

Handler, D., \& Epstein, A. S. (2010). Nature education in preschool. Highscope Extensions, 25(2), 1-7. Retrieved from: http://membership.highscope.org/app/ issues/144.pdf

Harvest Resources (Producer). (2006). Leave no child inside: Outdoor ECE program environments: A study guide for early childhood education [DVD]. Available from: http://www.ecetrainers.com/content/leave-nochild-inside-outdoor-ece-program-environments

Health Canada. (2001). First Nations Head Start standards guide. Retrieved from: http://www.hc-sc.gc.ca/fniahspnia/pubs/famil/_develop/2003_ahs-papa-ref-guide/ index-eng.php

Hughes, E. (2007). Linking past to present to create an image of the child. Theory Into Practice, 46(1), 48-56.

Joyce, B., \& Calhoun, E. (2010). Models of professional development: A celebration of educators. Thousand Oaks, CA: Corwin.

Keeler, R. (2004). Outdoor play environments for the soul Canadian Children, 29(1), 43-46.

Kernan, M. (2010). Being confined within? Constructions of the good childhood and outdoor play in early childhood education and care settings in Ireland. Children and Society, 24(5), 371-385. doi:10.1111/ j.1099-0860.2009.00249.x

Lambert, B. E. (1999). Do school playgrounds trigger playground bullying? Canadian Children, 24(1), $25-31$

Litmus Films (Producer). (2008). Norway: Outdoor preschool [video]. Retrieved from: http://www. journeyman.tv/59748/short-films/outdoor-preschool. html

Little, H., \& Eager, D. (2010). Risk, challenge and safety: Implications for play quality and playground design. European Early Childhood Education Research Journal, 18(4), 497-513. doi:10.1080/135029 $3 X .2010 .525949$

Louv, R. (2005). Last child in the woods: Saving our children from nature deficit disorder. Chapel Hill, NC: Algonquin Books.

Mauffette, A. G. (1998). Revisiting your outdoor environment: Reasons to reshape, enrich, redevelop the outdoor space. Canadian Children, 23(2), 17-21.

McNaughton, K. (1995). An exploratory study of beliefs about play: The case of the Eastern Arctic. Canadian Children, 20(1), 21-23.
Miller, D. L. (2007). The seeds of learning: Young children develop important skills through their gardening experiences at a Midwestern early education program. Applied Environmental Education and Communication, 6(1), 49-66. doi:10.1080/15330150701318828

Moore, R. (1997). The need for nature: A childhood right. Social Justice, 24(3), 203-220.

Nature Action Collaborative for Children. (n.d.). Connecting the world's children with nature [slide show]. Retrieved from: http://worldforumfoundation. org/wf/wp/ initiatives/ nature-action-collaborative-forchildren/environmental-action-kit/ advocacy-tools/ multimedia/

New, R., Mardell, S. B., \& Robinson, D. (2005). Early childhood education as risky business: Going beyond what's "safe" to discovering what's possible. Early Childhood Research and Practice, 7(2), 1-16.

Nguyen, M. (2011). Closing the education gap: A case for Aboriginal early childhood education in Canada: A look at the Aboriginal Head Start program. Canadian Journal of Education 34(3). 229-248.

Nova Scotia Child Care Initiative Program Technical Group. Nova Scotia Mi'kmaq child care facility guidelines. (1998). Retrieved from: kinu.ns.ca/ downloads/child_care_guidelines.pdf

Red River College (Producer). (n.d.). Our children, our ways: Early childhood education in First Nation and Inuit communities [DVD]. Available from: http://www. rrc.mb.ca/ ece/default.htm

Rivkin, M. (1997). The schoolyard habitat movement: What it is and why children need it. Early Childhood Education Journal, 25(1), 61-66.

Rowan, M. C. (2011). Exploring the possibilities of learning stories as a meaningful approach to early childhood education in Nunavik. Unpublished master's thesis, University of Victoria, British Columbia. Retrieved from: https://dspace.library. uvic.ca:8443/bitstream/handle/1828/3483/ Rowan_ Marycaroline_2011-1.pdf?sequence $=1$

Sandseter, E. B. H. (2009). Affordances for risky play in preschool: The importance of features in the play environment. Early Childhood Education Journal, 36(5), 439-446. doi:10.1007/s10643-009-0307-2

Staempfli, M. B. (2009). Reintroducing adventure into children's outdoor play environments. Environment and Behavior, 41(2), 268-280. doi:10.1177/0013916508315000

Stairs, A. H., \& Bernhard, J. K. (2002). Considerations for evaluating 'good care' in Canadian aboriginal early childhood settings. McGill Journal of Education, 37(3), 309-331.

Stephenson, A. (2003). Physical risk-taking: Dangerous or endangered? Early Years, 23(1), 35-43. doi: $10.1080 / 0957514032000045573$

Tucker, P. (2008). The physical activity levels of preschoolaged children: A systematic review. Early Childhood Research Quarterly, 23(4), 547-558. doi:10.1016/j. ecresq.2008.08.005

White, R. (2004). Young children's relationship with nature: Its importance to children's development and the earth's future. Children and Nature Network Retrieved from: http:/www.childrenandnature.org/ research/volumes/C16/16 